\title{
Circulating biomarkers of oxidative stress in normal pregnancy and preeclampsia and efficacy of antioxidant supplementation
}

\author{
Meena Khatri* \\ Department of Obstetrics \& Gynecology, Jawaharlal Nehru Medical College, Sawangi, Wardha, Maharashtra, India \\ Received: 3 May 2013 \\ Accepted: 25 May 2013 \\ *Correspondence: \\ Dr. Meena Khatri, \\ E-mail: meenakhatri619@yahoo.com \\ (C) 2013 Khatri M. This is an open-access article distributed under the terms of the Creative Commons Attribution Non- \\ Commercial License, which permits unrestricted non-commercial use, distribution, and reproduction in any medium, \\ provided the original work is properly cited.
}

\begin{abstract}
Background: To detect circulating markers of oxidative stress in women with normal pregnancy, women at risk of preeclampsia and women with preeclampsia and to assess the effect of Antioxidants on the levels of markers of oxidative stress in all the groups .

Methods: Quasi experimental study design, an experimental study with multiple arms conducted in the Department of Obstetrics and Gynecology at Jawaharlal Nehru Medical College, Sawangi (Meghe) Wardha from March 2009 to July 2012.

Results: Of 872 women enrolled, 290 were in the Normal Group (Normotensive women), 302 were in the At Risk Preeclampsia and 280 women allocated to Preeclampsia Group. Maximum numbers of pregnant women were between 20-24 years age group being $74.71 \%, 74.73 \%$ and $67.31 \%$ in the normal, at risk of Preeclampsia and preeclampsia group respectively Mean MDA level was $2.44 \mathrm{nmol} / \mathrm{ml}$ in normotensive women, $2.45 \mathrm{nmol} / \mathrm{ml}$ in at risk of preeclampsia and $4.83 \mathrm{nmol} / \mathrm{ml}$ in women with preeclampsia. SOD level in units/gm $\mathrm{Hb} \%$. Mean $\pm \mathrm{SD}$ was $9.58 \pm 6.44$ in normotensive group, $8.12 \pm 6.67$, in at risk of preeclampsia group and $6.88 \pm 14.90$ in preeclampsia group $(\mathrm{p}<0.05)$. This is due to antioxidant defense against oxidative stress in preeclampsia with resultant fall in plasma levels of SOD. Rising levels of MDA with the progression of gestation in placebo groups of all the pregnant women (Normotensive, at risk of preeclampsia and preeclampsia) and decline in the levels in those patients supplemented with antioxidant vitamins was observed. However there was no definite trend of significant rise or fall in the level of superoxide dismutase enzyme except in preeclamptic women.

Conclusions: Circulating biomarker, MDA levels were raised significantly in women with preeclampsia. Superoxide dismutase, an antioxidant enzyme showed lower levels in preeclamptic patients. Following antioxidant supplementation marked improvement was noticed in the biochemical indices in all the major groups (normal pregnancy, pregnancy at risk of preeclampsia and preeclampsia). Vitamin supplementation has definite role in reducing the oxidative stress and maternal and perinatal morbidity.
\end{abstract}

Keywords: Preeclampsia, Oxidative stress, Malondialdehyde (MDA), Superoxide dismutase (SOD)

\section{INTRODUCTION}

Pregnancy is a physiological state accompanied by a high energy demand and an increased oxygen requirement. Various compensatory adaptive changes, including increased ventilation for enhanced oxygen demand, occur with advancing pregnancy to meet the increasing requirements for proper bodily functions of the mother to fulfil the needs of the foetus. Such a condition may be responsible for raised oxidative stress in pregnancy. ${ }^{1}$

Oxidative stress, defined as a disturbance in the prooxidant antioxidant balance in favor of the former, leading to potential damage. .,28 $^{28}$

In a healthy body, pro-oxidants (free radical species) and antioxidants remain in balance. When the balance is 
disrupted towards an overabundance of free radical species, oxidative stress (OS) occurs. There is growing literature on the effects of oxidative stress in female reproduction with involvement in the pathophysiology of preeclampsia, gestational diabetes, hydatidiform mole, free radical induced birth defects and other situation such as abortions and preterm labour.

\section{METHODS}

Quasi experimental study design, an experimental study with multiple arms conducted in the Department of Obstetrics and Gynecology at Jawaharlal Nehru Medical College, Sawangi (Meghe) Wardha from March 2009 to July 2012. The study was approved by Institutional Ethics committee.

Total 872 pregnant women volunteered and gave written consent (consent was taken in vernacular language) for the study and comprised the study population after following inclusion criteria.

Sample size was estimated by using formula $[n=(4 \mathrm{x} \mathrm{p} \mathrm{x}$ $\mathrm{q} / \mathrm{L} \mathrm{x} \mathrm{L}$ ), Where $\mathrm{P}$ is the prevalence of preeclampsia (5$11 \%), q=1-p$ and $\mathrm{L}$ is Allowable Error (10-20\% of P)].

\section{Inclusion Criteria}

1. Primigravidae with singleton pregnancy between 20-32 weeks of gestation with Blood Pressure < 140/90 mmHg without proteinuria and edema.

2. Primigravidae with singleton pregnancy with mild preeclampsia between 20-32 weeks of pregnancy with Blood Pressure $\geq 140 / 90 \mathrm{mmHg}$ with proteinuria or edema $^{4,5}$ (proteinuria detected by dipstick test).

3. Pregnant women at risk of preeclampsia (those with family history of hypertension, previous history of preeclampsia, multifetal gestation, doppler changes showing diastolic notch in uterine artery at 20-24 weeks of pregnancy, all nulliparous patients, teen age pregnancy and pregnant women with age more than 35 years) ${ }^{6}$, After complete evaluation they were divided in three groups.

Group 1- Normotensive Primigravidae with singleton pregnancy between 20-32 weeks $(n=290)$.

Group 2- Primigravidae with Mild preeclampsia with singleton pregnancy between $20-32$ weeks $(n=280)$.

Group 3- Pregnant women at risk of preeclampsia between 20-32 weeks $(n=302)$.

For the purpose of this study, apart from routine investigation $(\mathrm{Hb}$, Blood group, VDRL, HIV, Blood sugar and USG and fundoscopy for patients with preeclampsia) following specific circulating biomarkers of oxidative stress were estimated using standard protocol.

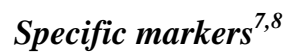

1. Serum malondialdehyde level (MDA): An end product of lipid peroxidation measured by thiobarbituric acid reactive substances assay (MDA-TBAR).

2. Superoxide Dismutase (SOD): An antioxidant enzyme measured by pyrogallol oxidation method.

Initial blood samples collected at first visit (at entry of study, 20 weeks onwards) were taken as control. After the first blood samples were taken and analyzed for circulating biomarkers of oxidative stress, patients were assigned to receive study medication either vitamin $\mathrm{C}$ $1000 \mathrm{mg}$ or vitamin E $400 \mathrm{IU}$ or vitamin C $1000 \mathrm{mg}$ and vitamin E 400 IU daily ${ }^{9,10}$ or placebo tablets in the same dosage for three months and were called for follow up at monthly interval for serial monthly measurement of biomarkers for three months (study medication was provided in brown paper pack prepared by hospital staff not involved in research and clinical management and it was provided free of cost). Patients with preeclampsia were given antihypertensive treatment Alfa methyl dopa $250 \mathrm{mg}$ 8hrly and were advised to come for follow up every 15 days, for BP monitoring and fetal growth monitoring and those patients who developed complications were hospitalised for active intervention.

\section{Statistical Analysis}

Statistical analysis was done by using descriptive and inferential statistics using chi-square test, one way ANOVA, Multiple Comparison-Tukey Test and Pearson's Correlation Coefficient. The software used in the analysis were SPSS (Statistical Package for Social Sciences) version 17.0 and GraphPad Prism version 5.0. All the results were tested at $5 \%$ level of significance.

\section{RESULTS}

Table 1: Distribution of patients in three groups.

\begin{tabular}{|llll|}
\hline Total Patients $\mathbf{n = 8 7 2}$ & Normal (Normotensive) & At risk preeclampsia & Preeclampsia \\
\hline Sample Size & 290 & 302 & 280 \\
\hline Lost to follow up & $29(10 \%)$ & $21(6.95 \%)$ & $20(7.14 \%)$ \\
\hline Total Patients remaining (802) & $261(87 \%)$ & $281(93.67 \%)$ & $260(86.67 \%)$ \\
\hline Placebo & 66 & 71 & 65 \\
\hline Vitamin C & 65 & 70 & 65 \\
\hline Vitamin E & 65 & 70 & 65 \\
\hline Vitamin C+E & 65 & 70 & 65 \\
\hline
\end{tabular}


Table 2: Age wise distribution of patients in three groups.

\begin{tabular}{|c|c|c|c|c|c|}
\hline $\begin{array}{l}\text { Age Group } \\
\text { (yrs) }\end{array}$ & Normal & $\begin{array}{l}\text { At risk } \\
\text { preeclampsia }\end{array}$ & Preeclampsia & $\aleph 2$-value & p-value \\
\hline $20-24$ & $195(74.71 \%)$ & $210(74.73 \%)$ & $175(67.31 \%)$ & \multirow{8}{*}{4.01} & \multirow{8}{*}{$\begin{array}{l}0.67 \mathrm{NS}, \\
\mathrm{p}>0.05\end{array}$} \\
\hline $25-29$ & $55(21.07 \%)$ & $57(20.28 \%)$ & $71(27.31 \%)$ & & \\
\hline $30-34$ & $11(4.21 \%)$ & $13(4.63 \%)$ & $11(4.23 \%)$ & & \\
\hline $35-39$ & $0(0.00 \%)$ & $1(0.36 \%)$ & $3(1.15 \%)$ & & \\
\hline Total & $261(100 \%)$ & $281(100 \%)$ & $260(100 \%)$ & & \\
\hline Mean & 22.92 & 23.04 & 23.42 & & \\
\hline SD & 2.88 & 2.95 & 3.20 & & \\
\hline Range & $20-34$ & $20-35$ & $30-35$ & & \\
\hline
\end{tabular}

Table 3: Comparison of MDA in three groups descriptive statistics.

\begin{tabular}{|lllllllll} 
Group & N & Mean & $\begin{array}{l}\text { Std. } \\
\text { Deviation }\end{array}$ & $\begin{array}{l}\text { Std. } \\
\text { Error }\end{array}$ & $\begin{array}{l}\text { 95\% Confidence } \\
\text { Interval for Mean }\end{array}$ & $\begin{array}{l}\text { Lower } \\
\text { Limit }\end{array}$ & $\begin{array}{l}\text { Upper } \\
\text { Limit }\end{array}$ & Minimum \\
Normal & 261 & 2.44 & 1.23 & 0.07 & 2.29 & 2.59 & 0.44 & 7.30 \\
\hline $\begin{array}{l}\text { At risk } \\
\text { Preeclampsia }\end{array}$ & 281 & 2.45 & 1.26 & 0.07 & 2.31 & 2.60 & 0.48 & 7.76 \\
\hline Preeclampsia & 260 & 4.83 & 2.31 & 0.14 & 4.54 & 5.11 & 0.97 & 16.40 \\
\hline
\end{tabular}

Table 4: Comparison of SOD in three groups descriptive statistics.

\begin{tabular}{|llllllllll} 
Group & N & Mean & $\begin{array}{l}\text { Std. } \\
\text { Deviation }\end{array}$ & $\begin{array}{l}\text { Std. } \\
\text { Error }\end{array}$ & $\begin{array}{l}\text { 95\% Confidence } \\
\text { Interval for Mean }\end{array}$ & $\begin{array}{l}\text { Lower } \\
\text { Limit }\end{array}$ & $\begin{array}{l}\text { Upper } \\
\text { Limit }\end{array}$ & Minimum & Maximum \\
\hline Normal & 261 & 9.58 & 6.44 & 0.39 & 8.79 & 10.36 & 0.56 & 32.59 \\
\hline $\begin{array}{l}\text { At risk } \\
\text { Preeclampsia }\end{array}$ & 281 & 8.12 & 6.67 & 0.39 & 7.33 & 8.90 & 0.52 & 32.59 \\
\hline Preeclampsia & 260 & 6.88 & 14.90 & 0.92 & 5.06 & 8.70 & 0.28 & 96.22 \\
\hline
\end{tabular}

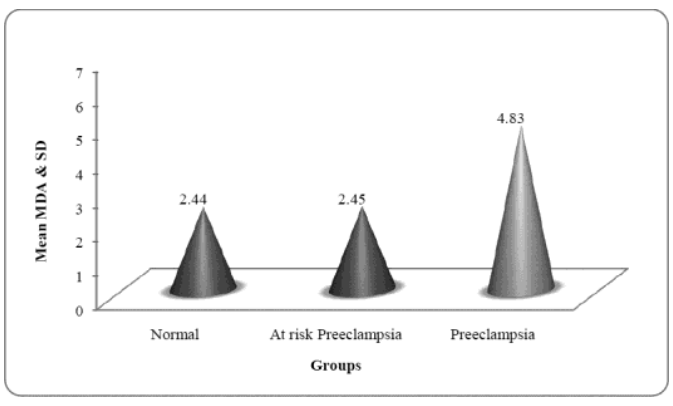

Figure 1: Comparison of MDA in three groups.

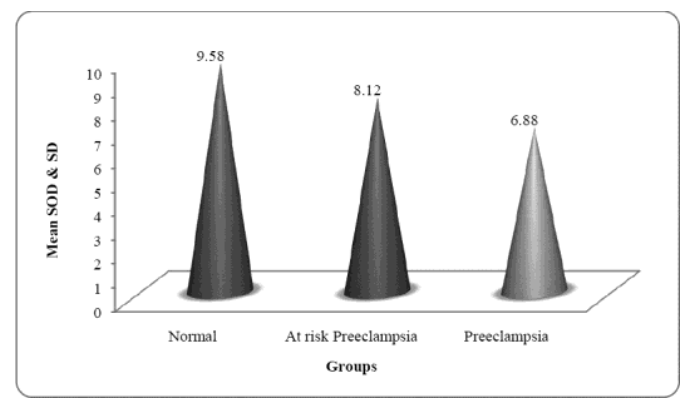

Figure 2: Comparison of SOD in three groups. 
Table 5: Post antioxidant levels of stress markers in three groups (serial monthly measurement).

\begin{tabular}{|c|c|c|c|c|c|c|c|c|c|}
\hline \multirow{2}{*}{ Subgroup } & \multirow{2}{*}{ Groups } & \multicolumn{4}{|l|}{ MDA } & \multicolumn{4}{|l|}{ SOD } \\
\hline & & Control & $1 \mathrm{mth}$ & $2 \mathrm{mth}$ & $3 \mathrm{mth}$ & Control & $1 \mathrm{mth}$ & $2 \mathrm{mth}$ & $3 \mathrm{mth}$ \\
\hline \multirow{3}{*}{ Placebo } & $\mathrm{N}$ & 2.19 & 2.33 & 2.44 & 2.61 & 10.17 & 9.93 & 9.21 & 8.74 \\
\hline & ARPE & 2.52 & 2.61 & 2.77 & 2.86 & 7.29 & 7.28 & 7.47 & 7.32 \\
\hline & $\mathrm{PE}$ & 4.82 & 5.12 & 5.46 & 5.93 & 16.64 & 17.12 & 18.60 & 19.11 \\
\hline \multirow{3}{*}{ Antioxidant } & $\mathrm{N}$ & 2.53 & 2.45 & 2.25 & 2.01 & 9.58 & 10.06 & 10.02 & 9.86 \\
\hline & ARPE & 2.43 & 2.38 & 2.22 & 2.01 & 8.12 & 8.99 & 9.02 & 8.92 \\
\hline & PE & 4.83 & 4.73 & 4.60 & 4.50 & 6.88 & 3.88 & 3.92 & 3.89 \\
\hline
\end{tabular}

Table 6: Maternal outcome in three groups.

\begin{tabular}{|lllllll|} 
& Normal & \multicolumn{3}{c|}{ ARPE } \\
& Placebo & Antioxidant & Placebo & Antioxidant & Placebo & Antioxidant \\
\hline PE & $10(15.15 \%)$ & $21(10.76 \%)$ & $12(16.90 \%)$ & $19(9.04 \%)$ & - & - \\
\hline Severe PE & - & - & $2(2.81 \%)$ & $1(0.47 \%)$ & $3(4.61 \%)$ & - \\
\hline Imminent Eclampsia & - & - & - & - & $3(4.61 \%)$ & $5(2.56 \%)$ \\
\hline Eclampsia & - & $1(0.51 \%)$ & $1(1.40 \%)$ & - & - & $3(1.53 \%)$ \\
\hline Abruptio Placenta & $1(0.51 \%)$ & - & $1(0.47 \%)$ & - & $3(4.61 \%)$ & $1(0.51 \%)$ \\
\hline HELLP & - & - & - & - & - & $3(1.53 \%)$ \\
\hline Preterm Labour & $7(10.66 \%)$ & $11(5.64 \%)$ & $8(12.30 \%)$ & - & $14(19.71 \%)$ & $12(5.71 \%)$ \\
\hline Oligohydramnios & $2(3.03 \%)$ & $2(1.03 \%)$ & $3(4.22 \%)$ & $2(0.95 \%)$ & $11(16.92 \%)$ & $4(2.05 \%)$ \\
\hline Severe Oligo & - & - & - & - & - & $1(0.51 \%)$ \\
\hline PPH & - & $1(0.51 \%)$ & - & $1(0.47 \%)$ & $7(10.76 \%)$ & $5(2.56 \%)$ \\
\hline Thrombocytopenia & $1(1.53 \%)$ & - & $2(2.81 \%)$ & $1(0.47 \%)$ & $3(4.61 \%)$ & $1(0.51 \%)$ \\
\hline Pulmonary Edema & - & - & - & - & - & - \\
\hline Maternal Death & - & - & - & - & - & - \\
\hline
\end{tabular}

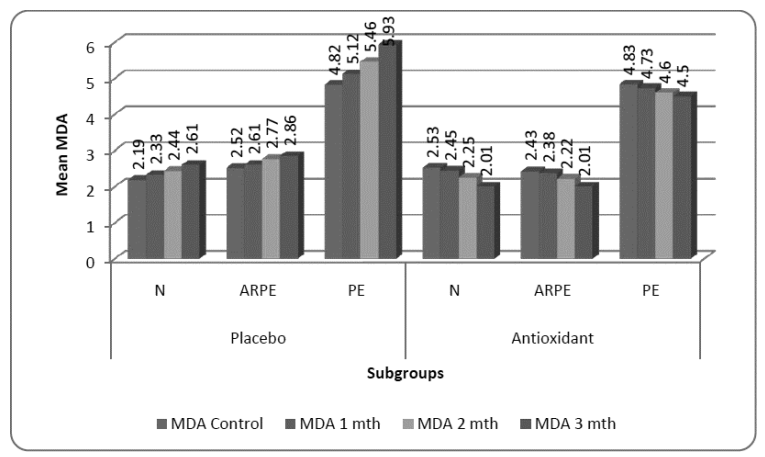

Figure 3: Post Antioxidant levels of stress marker in three groups: MDA.

Of the 872 women enrolled, 290 were in the Normal Group (Normotensive women), 302 were in the At Risk Preeclampsia and 280 women allocated to Preeclampsia Group (Table 1). The groups were comparable with regard to entry characteristics. Maximum numbers of pregnant women were between 20-24 years age group being $74.71 \%, 74.73 \%$ and $67.31 \%$ in the normal, At risk of Preeclampsia and preeclampsia group respectively (Table 2). Mean MDA level was $2.44 \mathrm{nmol} / \mathrm{ml}$ in normotensive women, $2.45 \mathrm{nmol} / \mathrm{ml}$ in at risk of preeclampsia and $4.83 \mathrm{nmol} / \mathrm{ml}$ in women with preeclampsia (Table 3).

Table 4 shows SOD level in units/gm Hb\%. Mean \pm SD was $9.58 \pm 6.44$ in normotensive group, $8.12 \pm 6.67$, in at risk of preeclampsia group and $6.88 \pm 14.90$ in preeclampsia group $(\mathrm{p}<0.05)$. This is due to antioxidant defense against oxidative stress in preeclampsia with resultant fall in plasma levels of SOD. Table 5 shows rising levels of MDA with the progression of gestation in placebo groups of all the pregnant women (Normotensive, at risk of preeclampsia and preeclampsia) and decline in the levels in those patients supplemented 
with antioxidant vitamins was observed. However there was no definite trend of significant rise or fall in the level of superoxide dismutase enzyme except in preeclamptic women.

Table 6 shows maternal morbidity.

\section{Preeclampsia}

Incidence of preeclampsia was $10(15.15 \%)$ in placebo and $21(10.76 \%)$ in antioxidant group $(R R=1.18, p=0.12)$ whereas in women at risk of preeclampsia it was $12(16.90 \%)$ and $19(9.04 \%)$ in placebo and antioxidant group respectively $(\mathrm{RR}=1.37, \mathrm{p}=0.14)$.

\section{Eclampsia}

Out of four patients admitted with convulsions, 1(0.51\%) was from antioxidant subgroup of normal $(\mathrm{RR}=0.00$, $\mathrm{p}=1.00)$ and $1(1.40 \%)$ from placebo of at risk preeclampsia $(\mathrm{RR}=0.00, \mathrm{p}=1.00)$ and $3(1.53 \%)$ were from antioxidant subgroup of preeclampsia $(0.00, \mathrm{p}=0.49)$.

\section{Abruptio Placenta}

Out of 6 patients of abruptio placenta $3(4.61 \%)$ were from the placebo subgroup of preeclampsia, 1 each $(0.51 \%, 1.40 \%)$ from placebo subgroup of normal and at risk preeclampsia respectively

\section{Preterm Labour}

Incidence of preterm labour was highest in preeclampsia group $(26(10 \%), \mathrm{RR}=1.67, \mathrm{p}=0.005)$ followed by women at risk of preeclampsia $8(12.30 \%), \mathrm{RR}=2.13, \mathrm{p}=0.0003)$, and normotensive patients $18(16.30 \%), \quad \mathrm{RR}=1.33$, $\mathrm{p}=0.31$ ).

\section{DISCUSSION}

In this quasi experimental study, table 1 shows distribution of patients in three groups (261, normotensive, 281 at risk of preeclampsia and 280 preeclampsia). They were further divided in subgroups based on vitamin supplementation.

Sociodemographic features of the patients were comparable, no significant difference was found between clinical features of preeclampsia and the normotensive pregnant control, (at the entry of study) other than hypertension, proteinuria and oedema.

End product of lipid peroxidation, marker of oxidative stress was measured by MDA- TBAR assay.

In this study serum MDA levels compared between three groups and levels were raised in women with preeclampsia and showed significant difference with normal and women at risk of preeclampsia $(\mathrm{p}<0.05)$. Many studies confirm that levels of lipid peroxidation products such as MDA and lipid peroxides are increased in pregnancy and show significant rise in the levels in women with preeclampsia.

JJ Wu (1996) ${ }^{11}$ found raised MDA levels in pregnant women with preeclampsia. Serum MDA levels were raised in women with preeclampsia or eclampsia pregnancies compared with uncomplicated pregnancy. suggesting that lipid peroxidation is an important factor in the pathogenesis of preeclampsia.

Comparative studies of MDA (nmol/ml):

\begin{tabular}{|lll|}
\hline Author and Year & Preeclampsia & $\begin{array}{l}\text { Normal } \\
\text { Pregnancy }\end{array}$ \\
\hline $\begin{array}{l}\text { Niyazi Tug et al } \\
(2003)^{12}\end{array}$ & $1.9 \pm 0.2$ & $0.84 \pm 0.2$ \\
\hline $\begin{array}{l}\text { Mohanty S. et al } \\
(2006)^{13}\end{array}$ & $4.90 \pm 2.02$ & $2.48 \pm 1.47$ \\
\hline $\begin{array}{l}\text { Mohd. Suhail } \\
(2008)^{14}\end{array}$ & $10.64 \pm 2.62$ & $7.98 \pm 2.92$ \\
\hline $\begin{array}{l}\text { J.B. Sharma et al } \\
(2009)\end{array}$ & $6.68 \pm 1.76$ & $2.35 \pm 0.76$ \\
\hline $\begin{array}{l}\text { Present Study } \\
(2012)\end{array}$ & $4.83 \pm 2.31$ & $2.44 \pm 1.23$ \\
\hline
\end{tabular}

Above table shows comparative values of MDA in preeclampsia and normal pregnancy reported by various authors. Present study is comparable with the studies by Mohanty S.et al (2006) and J.B. Sharma et al (2009).

\section{Superoxide dismutase (SOD)}

Table 4 shows Mean \pm SD plasma superoxide dismutase (SOD) levels of preeclampsia group were significantly decreased compared to normal group and at risk of preeclampsia group. Further the magnitude of oxidative stress and antioxidant SOD level changes correlated well with diastolic blood pressure.

Necipllhana et al, (2002) found significantly increased levels of malondialdehyde and $\mathrm{Cu}$ and decreased SOD and $\mathrm{Zn}$ in women with preeclampsia compared to normal group. Our findings give support that radical scavenger SOD is consumed by the increased lipid peroxidation in preeclampsia. This may indicate an involvement of free radicals in the pathophysiology of preeclampsia. Mahadik $\mathrm{KV}$ (2003) et $\mathrm{al}^{15}$ conducted a study of serum levels of superoxide dismutase in preeclampsia and eclampsia to test the predictive value and found low levels of SOD, less than $0.52 \mathrm{U} / \mathrm{ml}$ being the predecessor of fulminating eclampsia. Thus they concluded that low serum SOD levels are important in deciding the time of intervention as termination of pregnancy.

Table 5 shows comparison of maternal biomarkers (MDA and SOD) between Placebo and Antioxidant (Vitamin C, $\mathrm{E}$ and $\mathrm{C}+\mathrm{E}$ ) group (Control value, 1 month, 2 months and 3 months). Those women in the placebo subgroup show progressive rise in the levels of MDA in all the major 
groups i.e. Normotensive, At risk of Preeclampsia and Preeclampsia and women who received Antioxidant vitamin $\mathrm{C} / \mathrm{E} / \mathrm{C}+\mathrm{E}$ shows significant fall in the levels of MDA. Chappell et al, (1999) ${ }^{16}$ tested the efficacy of Antioxidant supplementation ( before clinically evident disease) in high risk women and found, supplementation with Vitamin $\mathrm{C}$ and $\mathrm{E}$ was associated with a $21 \%$ decrease in the PAI-1/PAI-2 ratio during gestation $(95 \%$ CI 4-35; $\mathrm{p}=0.015)$. They thus concluded that antioxidant supplementation in women who were at risk of preeclampsia was associated with improvement in biochemical indices of the disease.

Comparison of vitamins showed better results with vitamin $\mathrm{C}$, as vitamin $\mathrm{C}$ is scavenger of superoxide radicals and may help to preserve nitric oxide, also it is a chain breaking antioxidant and helps to maintain intracellular glutathione concentration. It was seen that there were rising levels of MDA with the progression of gestation in placebo subgroups of all the pregnant women i.e. normotensive, at risk of preeclampsia and preeclampsia and decline in the levels in those patients supplemented with antioxidant vitamins. Ghate $\mathbf{J}$ et al $(2011)^{17}$ found rise in oxidative stress with progression of gestation.

Table 5 shows positive correlation between MDA and SOD in placebo group of preeclampsia higher levels of SOD were found in placebo of preeclampsia as initial response to counteract the free radicals. However levels of SOD remains unchanged in normal and women at risk of preeclampsia of placebo this shows that bodies defence system is activated only in response to exceedingly higher value of MDA.

No major side effects were observed except for nausea and vomiting in few patients and abdominal pain and belching in those patients supplemented with combination of vitamin C $1000 \mathrm{mg}$ and vitamin E $400 \mathrm{IU}$.

\section{Maternal Outcome}

In this experimental study giving pregnant women supplementation of $1000 \mathrm{mg}$ of vitamin $\mathrm{C}$ and $400 \mathrm{IU}$ of Vitamin $\mathrm{E}$ and combination of vitamin $\mathrm{C}$ and $\mathrm{E}$ during pregnancy reduced the risk of preeclampsia in normal group or at risk of preeclampsia group. Maternal vitamin supplementation was not associated with a reduction in the risk of severe preeclampsia or imminent eclampsia and eclampsia. There was no significant difference in the severity of disease (Hepatic/ Renal Dysfunction) and use of magnesium sulphate or induction of labour because of hypertension. Vitamin supplementation was associated with reduction in risk of Abruptio Placenta. There was significant difference in the rate of preterm birth between vitamin supplemented and placebo subgroup. Higher rate of oligohydramnios was noted in placebo subgroup of preeclampsia. There was no difference in incidence of postpartum haemorrhage.
Results of the study indicate that although daily supplementation with vitamins during pregnancy has reduced the incidence of preeclampsia but vitamin supplementation during antenatal period didn't prevent preeclampsia in all the pregnant women from normal and at risk of preeclampsia group.

\section{CONCLUSION}

- Circulating biomarker, MDA levels were raised significantly in women with preeclampsia.

- Superoxide dismutase, an antioxidant enzyme showed lower levels in preeclamptic patients.

- Following antioxidant supplementation marked improvement was noticed in the biochemical indices in all the major groups (normal pregnancy, pregnancy at risk of preeclampsia and preeclampsia).

- Vitamin supplementation has definite role in reducing the oxidative stress.

\section{ACKNOWLEDGEMENTS}

I am grateful to my guide Dr. Vijaya Patil under whose able guidance I conducted the study successfully, I am thankful to research laboratory incharge Dr. Swanand Pathak who helped me for estimation of markers of oxidative stress I am thankful to the head of institute who permitted me to conduct research for $\mathrm{PhD}$. Also I am grateful to Head of Department Obstetrics and Gynecology.

\section{REFERENCES}

1. Al-Shebly MM, Mansour MA. Evaluation of oxidative stress and antioxidant status in diabetic and hypertensive women during labor. Oxid Med Cell Longev. 2012;2012:329743.

2. Chamy V, Lepe J, Catalán A, Retamal D, Escobar J, Madrid E : Oxidative stress is closely related to clinical severity of pre-eclampsia, Biological Research 2006;39(2):229-36.

3. Agarwal A, Gupta S and Sharma R. Role of oxidative stress in female reproduction: Reproductive Biology and endocrinology 2005; vol.13 issue1, pages 28, 1122-49.

4. Gullmezoglu M, Hafmeyr G, Oosthuisen M : Antioxidants in the treatment of severe preeclamsia an explanatory randomized controlled trial : British Journal of Obstetrics and Gynecology, Jun 1997, Vol 104 Pg. 689-696.

5. Sharma J.B., Sharma A., Bahadur A., Vimala N., Satyam A., Mittal S. : Oxidative stress markers and antioxidant levels in normal pregnancy and preeclampsia,: International Journal of Gynecology and Obstetrics, 2006, 94, 23-27.

6. Sharma J. B., Mittal Suneeta : Prevention of Preeclampsia : Progress in obstetrics and Gynecology 2005; Vol 17; 141-163.

7. Ilhana N Ilhan N, Simsekc M : The changes of trace elements, malondialdehyde levels and superoxide 
dismutase activities in pregnancy with or without preeclampsia, Clinical Biochemistry : July 2002; 35 (5), pg 393-7.

8. Mahadik KV, Sina SA,: Study of serum levels of superoxide dismutase in preeclampsia and ecalmpsia : Role of the test as a predictive tool,: Research J Obstel Gynaecol, 2003 Aug:29(4):262-7.

9. Alice R., Rumbold A, Crowther C, Ross R., Dekker G A, and. Robinson S : Vitamin $\mathrm{C}$ and $\mathrm{E}$ and the risk of preeclampsia and perinatal complications : New England J. Med 2006; 354 : 1796-1806.

10. Desai P, Narayanan P : Role of Antioxidant Therapy to prevent Preeclampsia; Shah M :Hypertensive Disorders in Pregnancy : Jaypee Publisher NewDelhi India 2007 first Edition Pg. 293-298.

11. Wu JJ. Lipid peroxidation in preeclamptic and eclamptic pregnancies, European Journal obstetrics and gynecology and reproductive Biology, Jan 1996, vol 65, issue 1, pp 51-54.

12. Tug N, Celiu H, Ozcelik G.O, Ayar A.: T Tug N, Celiu H, Ozcelik G.O, Ayar A.: The correlation between plasma homocysteine and malondialdehyde levels in preeclampsia, Neuroendocrinology letter No. 6, Dec. 2003, Vol 24, pg. 445-448.

13. Mohanty S., Sahu P. K., Mandal M. K., Mohapatra P. C., Panda A. Evaluation of oxidative stress in pregnancy induced hypertension,: Indian Journal of clinical biochemistry, 2006, 21 (1) 101-105.

14. Suhail M, Suhail M. F, Khan H. Alterations in antioxidant and pro-oxidant balance in preeclampsia impact on erythrocyte osmotic fragility. Biochemia Medica 2008;18(3):331-41.

15. Mahadik KV, Sina SA. Study of serum levels of superoxide dismutase in preeclampsia and eclampsia: Role of the test as a predictive tool. Research J Obstet Gynaecol, 2003 Aug:29(4):262-7.

16. Chappell C, Paul S, Briley T, Annette L, Kelly F, Lee, Haunt R, Berverley J, Parmer K : Effect of antioxidant on occurrence of preeclampsia in women at increased risk; A randomized trial; The Lancet 1999; 354; 810-6.

17. Ghate J, Choudhari AR, Ghygare B. Singh Ramji. Antioxidant Role of Vitamin $\mathrm{C}$ in normal Pregnancy. Biomedical Research 2011;22(1):49-51.

DOI: $10.5455 / 2320-1770 . i j r \operatorname{cog} 20130909$

Cite this article as: Khatri M. Circulating biomarkers of oxidative stress in normal pregnancy and preeclampsia and efficacy of antioxidant supplementation. Int J Reprod Contracept Obstet Gynecol 2013;2:304-10. 